ISSN 1980-5098@®@ DOI: http://dx.doi.org/10.5902/1980509831608

\title{
A VEGETAÇ̃̃O NO PAISAGISMO DAS PRAÇAS DE CURITIBA - PR
}

\author{
VEGETATION IN THE LANDSCAPE OF CURITIBA SQUARES - PARANÁ STATE
}

\author{
Jennifer Viezzer ${ }^{1}$ Daniela Biondi ${ }^{2}$ Angeline Martini ${ }^{2}$ Mayssa Mascarenhas Grise ${ }^{3}$
}

\begin{abstract}
RESUMO
Para se investigar as funções ecológicas que as praças desempenham como áreas verdes urbanas, esta pesquisa teve o objetivo de inventariar e caracterizar a vegetação utilizada no paisagismo das praças de Curitiba - PR. Todas as espécies que ocorrem em 32 praças da cidade foram identificadas e quantificadas. Os resultados apontaram que foram encontradas 141 espécies, distribuídas em 58 famílias. Daquele total, 60,3\% são arbóreas e 56,7\% são de procedência exótica. A espécie que aparece em maior número de praças é Axonopus compressus (grama-são-carlos), presente em 96,9\% dos casos. Entre as espécies arbóreas, Ceiba speciosa (paineira) é a de maior ocorrência, aparecendo em $46,9 \%$ das praças. Rhododendron simsii (azaleia) apresentou o maior número de exemplares, com 438 indivíduos. É importante considerar o número de exemplares, a diversidade de espécies, e suas características para que os benefícios ecológicos proporcionados pelas praças possam ser garantidos.
\end{abstract}

Palavras-chave: arborização urbana; áreas verdes; diversidade.

\begin{abstract}
To investigate the ecological functions that squares play as urban green areas, this research was designed to inventory and characterize the vegetation used in the landscaping of the squares of Curitiba-PR state. All species occurring in 32 squares in the city were identified and quantified. Results show that 141 species were found, belonging to 58 families. Of this total, $60.3 \%$ of species are of arboreal life and $56.7 \%$ are of exotic origin. The species that appear in more places is Axonopus compressus (grama-são-carlos), present in $96.9 \%$ of cases. Between tree species, Ceiba speciosa (paineira) is the most frequent, appearing in $46.9 \%$ of the squares. Rhododendron simsii (azalea) had the highest number of individuals, with 438. It is important to consider the number of individuals, the diversity of species and their characteristics so that the ecological benefits provided by these squares can be guaranteed.
\end{abstract}

Keywords: urban forest; green areas; diversity.

\section{INTRODUÇÃO}

Mais de $50 \%$ da população mundial e $84 \%$ da população brasileira vivem hoje em centros urbanos (SECRETARIADO DA CONVENÇÃO DA DIVERSIDADE BIOLÓGICA, 2012; IBGE, 2010). As condições de artificialidade das cidades e os impactos da urbanização ocasionam prejuízos para o bem-estar e para a qualidade de vida da população, porém, parte destes impactos pode ser amenizada pela quantidade e qualidade da arborização urbana (MILANO, 1987).

As áreas verdes e as árvores de ruas desempenham serviços essenciais à melhoria das condições de vida das populações urbanas (VOLPE-FILIK; SILVA; LIMA, 2007; CRISPIM et al., 2014). A cidade

1 Engenheira Florestal, MSc., Analista Ambiental da Secretaria de Biodiversidade e Florestas, Ministério do Meio Ambiente, Anexo 1, SEPN 505, Bloco B, Edifício Marie Prendi Cruz, $4^{\circ}$ andar, sala 402, CEP 70730-542, Brasília (DF), Brasil. jennifer.viezzer@mma.gov.br

2 Engenheira Florestal, Dr ${ }^{\mathrm{a}}$., Professora Titular do Departamento de Ciências Florestais, Universidade Federal do Paraná, Campus Jardim Botânico, Centro de Ciências Florestais e da Madeira, Av. Pref. Lothário Meissner, 632, CEP 80210-170, Curitiba (PR), Brasil. dbiondi@ufpr.br/martine.angeline@gmail.com

3 Bióloga, Drª ., Programa de Pós-graduação em Engenharia Florestal, Universidade Federal do Paraná, Rua Ponta Grossa, 330, CEP 80610-160, Curitiba (PR), Brasil. mayssamonteiro@gmail.com

Recebido para publicação em 2/02/2016 e aceito em 13/09/2016

Ci. Fl., v. 28, n. 1, jan.- mar., 2018 
de Curitiba, capital do estado do Paraná, possui historicamente um forte discurso ambiental e uma política voltada à valorização da arborização urbana. Dentre estas políticas, está a de conservar as praças da cidade como locais ajardinados e arborizados (BAHLS, 2006).

A presença de vegetação nas praças desempenha diversos serviços ecossistêmicos que trazem benefícios ecológicos. As praças podem formar elos entre as demais áreas verdes e ruas arborizadas, formando corredores e criando oportunidades para o enriquecimento da biodiversidade (COSTA; ERJAVEC; MATHEY, 2008). A vegetação promove a melhoria microclimática, acústica, da qualidade do ar e da drenagem das águas pluviais; a proteção do solo contra erosão e a sobrevivência da fauna; sendo que as árvores, no geral, são essenciais para o bem-estar da população humana (BIONDI, 2008; ROBBA; MACEDO, 2010; MARTINI, 2013).

Além disso, a presença de vegetação nas áreas verdes proporciona a diversificação e o embelezamento da paisagem urbana através de linhas suaves e orgânicas, cores e molduras, tornando as praças objetos cênicos, referenciais e de identidade nas cidades (DE ANGELIS; DE ANGELIS NETO, 2000; BIONDI, 2008).

O objetivo desta pesquisa foi inventariar a vegetação utilizada no paisagismo das praças de Curitiba - PR.

\section{MATERIAL E MÉTODOS}

Curitiba possui 1.879.355 habitantes, distribuídos em uma área de 435,036 $\mathrm{km}^{2}$, com densidade demográfica de 4.320 hab. $/ \mathrm{km}^{2}$ (IBGE, 2016b; CURITIBA, 2016c). A cidade está localizada no Primeiro Planalto Paranaense, a 934,6 metros de altitude, e possui relevo levemente ondulado, com colinas suavemente arredondadas, dando-lhe uma fisionomia relativamente regular (INSTITUTO DE PESQUISA E PLANEJAMENTO URBANO DE CURITIBA, 2016).

Segundo classificação climática de Köppen-Geiger, Curitiba localiza-se em região climática do tipo $\mathrm{Cfb}$, com temperatura média anual de $17^{\circ} \mathrm{C}$, com média de $20,5^{\circ} \mathrm{C}$ no mês mais quente e $13^{\circ} \mathrm{C}$ no mês mais frio, e precipitação anual de $1.550 \mathrm{~mm}$ levemente concentrada nos meses de verão (ALVARES et al., 2013).

Curitiba está inserida dentro do Bioma Mata Atlântica, na região fitogeográfica da Floresta Ombrófila Mista, entremeada por fragmentos de Estepe Gramíneo-Lenhosa (BOBROWSKI, 2011). Segundo o mapa de maciços florestais de Curitiba (CURITIBA, 2016a), o índice de áreas verdes (IAV) é de $64,5 \mathrm{~m}^{2} / \mathrm{hab}$, o que representa $113 \mathrm{~km}^{2}$, ou $26 \%$ da superfície da capital coberta por vegetação. O índice de arborização urbana do IBGE (2016a) constatou que 76,4\% da cidade encontra-se arborizada. Das 1.066 áreas verdes existentes na cidade, 454 são praças, que ocupam $11,41 \%$ da extensão ocupada pelas áreas verdes em Curitiba (VIEZZER et al., 2012).

Utilizaram-se dois critérios para definir a população a ser estudada: possuir nome próprio e data de criação. Das 454 praças de Curitiba, 343 possuem nome, 101 possuem datas cadastradas na Secretaria Municipal do Meio Ambiente de Curitiba, e 56 praças possuem datas encontradas em documentos junto aos arquivos da Casa da Memória de Curitiba. Definiu-se a população a ser estudada em um total de 157 praças. Dessa população, foram sorteadas inicialmente 16 amostras $(10 \%)$ por meio do método de amostragem aleatória para um estudo-piloto. Neste estudo preliminar, foi realizado o levantamento de uma variável de interesse: a relação entre área permeável e a área total das praças. Por meio desta variável, foi possível realizar o cálculo do número de amostras necessárias para uma população finita proposta por Oliveira e Brune (1985). A amostragem inicial de 10\% das praças no estudo piloto permitiu o cálculo da quantidade adequada de praças a ser amostrada para que o resultado fosse considerado significativo. O cálculo foi realizado admitindo um limite de erro de $15 \%$ e uma probabilidade de $10 \%$. Por meio deste cálculo, mostrou-se necessário o levantamento da vegetação de 32 praças para que o estudo fosse significativo. Por isso, mais 16 praças foram sorteadas de maneira aleatória e somadas às 16 praças componentes do estudopiloto. Sendo assim, o levantamento da vegetação utilizada no paisagismo das praças de Curitiba - PR foi realizado em 32 praças, que representam 20,4\% da população definida de 157 praças.

Relação das 32 praças amostradas: Tiradentes, Carlos Gomes, José Borges de Macedo, Santos Andrade, Garibaldi, do Redentor, da Espanha, Pe. João Bagozzi, Alfredo Andersen, Villa Lobos, Abílio de Abreu, Itália, Isaac Milder, Presidente Eisenhower, Tobias Bueno de Arruda, Francisco R. A. de Macedo, 
Nova República, Lucia Bozza Pilatti, Piazza San Marco, Pe. Agostinho Legros, do Japão, Vívian Calopreso Braga, Nelson Satenarski Monteiro, Rio Iguaçu, Pe. Dario Zampiero, Profa. Rosa Kolody, da Colonização Menonita, Irene Pereira e Silva, Loris Scorsin, Emirados Árabes Unidos, Domingas Bianco Stoco e Prof. Dr. Manoel Lourenço Branco.

As espécies presentes nas 32 praças amostradas foram identificadas e quantificadas por uma equipe de campo, geralmente composta por três pesquisadores, que utilizaram equipamentos como prancheta e lápis, máquina fotográfica, tesoura de poda e podão aéreo para coleta de amostras da vegetação. A identificação das espécies foi realizada prioritariamente em campo no momento da coleta de dados, porém, quando esta identificação não foi possível, a vegetação foi coletada para identificação por meio de comparação de exsicatas depositadas no Laboratório de Paisagismo e no Herbário do curso de Engenharia Florestal UFPR e com base em literatura específica (LORENZI, 2002; CARVALHO, 2003; LORENZI et al., 2003; BIONDI; ALTHAUS, 2005; BIONDI; LEAL, 2008; LORENZI; SOUZA, 2008; TROPICOS, 2015). Depois de identificada, a vegetação foi caracterizada da seguinte forma: forma de vida (árvore, arbusto, herbácea, trepadeira), procedência (nativa de Curitiba, nativa do Brasil, exótica), número de indivíduos e praças de ocorrência.

\section{RESULTADOS E DISCUSSÃO}

Foram encontradas 141 espécies nas 32 praças amostradas, distribuídas em 58 famílias, conforme Tabela 1.

TABELA 1: Espécies encontradas nas praças de Curitiba - PR.

TABLE 1: Species found in the squares of Curitiba - PR state.

\begin{tabular}{|c|c|c|c|c|c|c|c|}
\hline N. & Nome popular & Nome científico & Família & F.V. & P. & $\begin{array}{l}\mathrm{N} . \\
\text { Ind. }\end{array}$ & Praças \\
\hline 1 & Abacate & Persea americana Mill. & Lauraceae & A & $\mathrm{E}$ & 4 & $2,14,19$ \\
\hline 2 & Ácer & Acer negundo L. & Aceraceae & A & $\mathrm{E}$ & 1 & 4 \\
\hline 3 & Açoita-cavalo & Luehea divaricata Mart. & Malvaceae & A & $\mathrm{NC}$ & 4 & 16,29 \\
\hline 4 & Agapanto & Agapanthus africanus (L.) Hoffmanns & Amaryllidaceae & $\mathrm{H}$ & $\mathrm{E}$ & - & $4,7,11$ \\
\hline 5 & Agave & Agave americana $\mathrm{L}$. & Asparagaceae & $\mathrm{B}$ & $\mathrm{E}$ & 30 & $11,21,27$ \\
\hline 6 & Agave-dragão & Agave attenuata Salm-Dyck & Asparagaceae & $\mathrm{B}$ & $\mathrm{E}$ & 1 & 8,11 \\
\hline 7 & Alamo & Populus nigra $\mathrm{L}$. & Salicaceae & A & $\mathrm{E}$ & 2 & 12,20 \\
\hline 8 & Alfeneiro & Ligustrum lucidum W.T. Aiton & Oleaceae & A & $\mathrm{E}$ & 35 & $2,7,18,21,25,27,30$ \\
\hline 9 & Amora & Morus nigra L. & Moraceae & A & $\mathrm{E}$ & 3 & $15,24,31$ \\
\hline 10 & Amor-perfeito & Viola wittrockiana Gams & Violaceae & $\mathrm{H}$ & $\mathrm{E}$ & - & $1,2,4,7,24$ \\
\hline 11 & Andira & Andira humilis Mart. ex Benth. & Fabaceae & $\mathrm{B}$ & $\mathrm{N}$ & 1 & 28 \\
\hline 12 & Angico & Parapiptadenia rigida (Benth.) Brenan & Fabaceae & A & $\mathrm{E}$ & 39 & $2,4,15,16,17,27$ \\
\hline 13 & Araçá & Psidium cattleyanum Sabine & Myrtaceae & A & $\mathrm{N}$ & 38 & $\begin{array}{c}1,2,4,10,11,15,18 \\
29,30\end{array}$ \\
\hline 14 & Araucária & Araucaria angustifolia (Bertol.) Kuntze & Araucariaceae & A & $\mathrm{NC}$ & 85 & $\begin{array}{c}1,2,4,5,7,10,14,16 \\
19,21,27,30\end{array}$ \\
\hline 15 & Ardísia & Ardisia crenata Sims & Myrsinaceae & $\mathrm{B}$ & $\mathrm{E}$ & 2 & 15,20 \\
\hline 16 & Aroeira & Schinus terebinthifolius Raddl. & Anacardiaceae & A & $\mathrm{NC}$ & 24 & $\begin{array}{c}2,7,11,12,17,23 \\
27,29\end{array}$ \\
\hline 17 & Aroeira-chorão & Schinus molle L. & Anacardiaceae & A & $\mathrm{N}$ & 4 & $7,25,31$ \\
\hline 18 & Avenca-japonesa & Nandina domestica Thunb. & Berberidaceae & $\mathrm{B}$ & $\mathrm{E}$ & 15 & 21 \\
\hline 19 & Azaleia & Rhododendron simsii Planch. & Ericaceae & $\mathrm{B}$ & $\mathrm{E}$ & 486 & $\begin{array}{c}2,4,5,7,18,20,21 \\
26,27\end{array}$ \\
\hline 20 & Babosa & Aloe sp. & Xanthorrhoeaceae & $\mathrm{B}$ & $\mathrm{E}$ & 2 & 21 \\
\hline 21 & Beijinho & Impatiens walleriana Hook. $\mathrm{f}$. & Balsaminaceae & $\mathrm{H}$ & $\mathrm{E}$ & - & 21 \\
\hline 22 & Beri-silvestre & Canna aureovittata Lodd. & Cannaceae & $\mathrm{B}$ & $\mathrm{N}$ & 1 & 2 \\
\hline
\end{tabular}

Continua... 
TABELA 1: Continuação...

TABLE 1: Continued...

\begin{tabular}{|c|c|c|c|c|c|c|c|}
\hline N. & Nome popular & Nome científico & Família & F.V. & P. & $\begin{array}{l}\mathrm{N} . \\
\text { Ind. }\end{array}$ & Praças \\
\hline 23 & Bico-de-papagaio & $\begin{array}{c}\text { Euphorbia pulcherrima Willd. ex } \\
\text { Klotzsch }\end{array}$ & Euphorbiaceae & B & $\mathrm{E}$ & 19 & $9,11,15,25,30$ \\
\hline 24 & Boldo-de-jardim & Plectranthus barbatus Andrews & Lamiaceae & $\mathrm{B}$ & $\mathrm{E}$ & 1 & 27 \\
\hline 25 & Bracatinga & Mimosa scabrella Benth. & Fabaceae & A & $\mathrm{NC}$ & 1 & 11 \\
\hline 26 & Buxinho & Buxus sempervirens L. & Buxaceae & $\mathrm{B}$ & $\mathrm{E}$ & 101 & $5,21,26$ \\
\hline 27 & Cacto & Cactus sp. & Cactaceae & $\mathrm{H}$ & $\mathrm{E}$ & - & 11 \\
\hline 28 & Cacto-candelabro & Euphorbia ingens E. Mey. ex Boiss. & Euphorbiaceae & $\mathrm{H}$ & $\mathrm{E}$ & - & 9,11 \\
\hline 29 & Caliandra-rosa & Caliandra brevipes Benth. & Fabaceae & B & $\mathrm{N}$ & 6 & $15,21,23,27$ \\
\hline 30 & Calistemon & Callistemon citrinus (Curtis) Skeels & Myrtaceae & B & $\mathrm{N}$ & 15 & $2,10,12$ \\
\hline 31 & Camboatá & Matayba elaeagnoides Radlk. & Sapindaceae & A & $\mathrm{N}$ & 3 & 11,28 \\
\hline 32 & Camélia & Camelia japonica $\mathrm{L}$. & Theaceae & A & $\mathrm{E}$ & 5 & 21 \\
\hline 33 & Canafístula & Peltophorum dubium (Spreng.) Taub. & Fabaceae & A & $\mathrm{N}$ & 41 & $\begin{array}{c}2,9,10,11,14,17,18 \\
21,23,24,27,29\end{array}$ \\
\hline 34 & Canudo-de-pito & Senna bicapsularis (L.) Roxb. & Fabaceae & A & $\mathrm{E}$ & 1 & 11 \\
\hline 35 & Capim-limão & Cymbopogon citratus (DC.) Stapf & Poaceae & $\mathrm{H}$ & $\mathrm{E}$ & - & 20 \\
\hline 36 & Capororoca & Myrsine guianensis (Aubl.) Kuntze & Primulaceae & A & $\mathrm{NC}$ & 1 & 11 \\
\hline 37 & Capororoca & Myrsine umbellata Mart. & Primulaceae & A & $\mathrm{NC}$ & 1 & 11 \\
\hline 38 & Cássia-fastuosa & Cassia leptophylla Vogel & Fabaceae & A & $\mathrm{N}$ & 40 & $4,12,15,16,27$ \\
\hline 39 & Cássia-manduirana & $\begin{array}{c}\text { Senna macranthera (DC. Ex Collard.) } \\
\text { H. S. Irwin \& Barneby }\end{array}$ & Fabaceae & A & $\mathrm{N}$ & 2 & 16,19 \\
\hline 40 & Cássia-multijuga & $\begin{array}{c}\text { Senna multijuga (Rich.) H. S. Irwin \& } \\
\text { Barneby }\end{array}$ & Fabaceae & A & $\mathrm{N}$ & 9 & 4,21 \\
\hline 41 & Casuarina & Casuarina equisetifolia $\mathrm{L}$. & Casuarinaceae & A & $\mathrm{E}$ & 53 & 27 \\
\hline 42 & Caterete & Machaerium paraguariense Hassl. & Fabaceae & A & $\mathrm{NC}$ & 2 & 18 \\
\hline 43 & Cedro-europeu & $\begin{array}{c}\text { Chamaecyparis obtusa (Siebold \& } \\
\text { Zucc.) Endl. }\end{array}$ & Cupressaceae & A & $\mathrm{E}$ & 36 & 7,9 \\
\hline 44 & Cedro-rosa & Cedrela fissilis Vell. & Meliaceae & A & $\mathrm{NC}$ & 1 & 23 \\
\hline 45 & Cereja-do-japão & Prunus serrulata Lindl. & Rosaceae & A & $\mathrm{E}$ & 24 & 21,30 \\
\hline 46 & Cheflera & Schefflera arboricola (Hayata) Merr. & Araliaceae & B & $\mathrm{E}$ & 2 & 7,11 \\
\hline 47 & Chorão & Salix babylonica L. & Salicaceae & A & $\mathrm{E}$ & 1 & 15 \\
\hline 48 & Cica & Cycas revoluta Thunb. & Cycadaceae & B & $\mathrm{E}$ & 7 & 21 \\
\hline 49 & Cinamomo & Melia azedarach L. & Meliaceae & A & $\mathrm{E}$ & 22 & $6,7,11,16,31$ \\
\hline 50 & Cipreste & Cupressus lusitanica Mill. & Cupressaceae & A & $\mathrm{E}$ & 2 & 2 \\
\hline 51 & Clusia & Clusia fluminensis Planch. \& Triana & Clusiaceae & B & $\mathrm{N}$ & 30 & 1,18 \\
\hline 52 & Coroa-de-cristo & Euphorbia milii Des Moul. & Euphorbiaceae & $\mathrm{B}$ & $\mathrm{E}$ & 8 & 23 \\
\hline 53 & Corticeira & Erythrina crista-galli L. & Fabaceae & A & $\mathrm{NC}$ & 4 & 4 \\
\hline 54 & Cotoneaster & Cotoneaster franchetti Bois & Rosaceae & B & $\mathrm{E}$ & 2 & 17 \\
\hline 55 & Criptoméria & $\begin{array}{c}\text { Cryptomeria japonica (Thunb. Ex L. F.) } \\
\text { D. Don }\end{array}$ & Taxodiaceae & A & $\mathrm{E}$ & 1 & 30 \\
\hline 56 & Cróton & $\begin{array}{c}\text { Codiaeum variegatum (L.) Rumph. ex } \\
\text { A. Juss. }\end{array}$ & Euphorbiaceae & B & $\mathrm{E}$ & 1 & 21 \\
\hline 57 & Dama-da-noite & Cestrum nocturnum $\mathrm{L}$. & Solanaceae & B & $\mathrm{E}$ & 1 & 26 \\
\hline 58 & Dedaleiro & Lafoensia pacari A. St.-Hill. & Lithraceae & A & $\mathrm{NC}$ & 66 & $\begin{array}{l}1,2,7,11,12,13,15 \\
16,20,23,27,30\end{array}$ \\
\hline 59 & Dracena & Dracaena marginata hort. & Asparagaceae & $\mathrm{B}$ & $\mathrm{E}$ & 6 & $9,11,21$ \\
\hline 60 & Embuia & Ocotea porosa (Nees \& Mart.) Barroso & Lauraceae & A & $\mathrm{NC}$ & 2 & 12 \\
\hline
\end{tabular}

Continua... 
TABELA 1: Continuação...

TABLE 1: Continued...

\begin{tabular}{|c|c|c|c|c|c|c|c|}
\hline N. & Nome popular & Nome científico & Família & F.V. & P. & $\begin{array}{l}\mathrm{N} . \\
\text { Ind. }\end{array}$ & Praças \\
\hline 61 & Erva-mate & Ilex paraguariensis A. St.-Hill. & Aquifoliaceae & A & $\mathrm{NC}$ & 1 & 4 \\
\hline 62 & Espirradeira & Nerium oleander L. & Apocynaceae & B & $\mathrm{E}$ & 2 & 11,12 \\
\hline 63 & Eucalipto & Eucalyptus cinearea F. Muell. Ex Benth. & Myrtaceae & A & $\mathrm{E}$ & 14 & 11,24 \\
\hline 64 & Extremosa & Lagerstroemia indica $\mathrm{L}$. & Lithraceae & A & $\mathrm{E}$ & 29 & $2,4,11,13,21,24$ \\
\hline 65 & Falso-hibisco & Malvaviscus arboreus Cav. & Malvaceae & B & $\mathrm{E}$ & 1 & 4 \\
\hline 66 & Ficus & Ficus benjamina $\mathrm{L}$. & Moraceae & A & $\mathrm{E}$ & 6 & $7,9,11,26$ \\
\hline 67 & Ficus-variegata & Ficus benjamina variegata $\mathrm{L}$. & Moraceae & A & $\mathrm{E}$ & 2 & 18 \\
\hline 68 & Figueira & Ficus gomelleira Kunth \& C. D. Bouché & Moraceae & A & $\mathrm{N}$ & 5 & 1 \\
\hline 69 & Glicínia & Wisteria floribunda (Willd.) DC. & Fabaceae & $\mathrm{T}$ & $\mathrm{E}$ & - & 21 \\
\hline 70 & Goiaba & Psidium guajava $\mathrm{L}$ & Myrtaceae & A & $\mathrm{N}$ & 3 & $15,19,24$ \\
\hline 71 & Grama-amendoim & Arachis repens Handro & Fabaceae & $\mathrm{H}$ & $\mathrm{N}$ & - & $2,20,21$ \\
\hline 72 & Grama-preta & Aphiopogon japonicus (L. f.) Ker Gawl. & Asparagaceae & $\mathrm{H}$ & $\mathrm{E}$ & - & $2,4,20$ \\
\hline 73 & Grama-são-carlos & Axonopus compressus (Sw.) P. Beauv. & Poaceae & $\mathrm{H}$ & $\mathrm{NC}$ & - & *todas exceto 6 \\
\hline 74 & Guabiroba & Campomanesia xanthocarpa O. Berg & Myrtaceae & A & $\mathrm{NC}$ & 11 & $1,2,4,11$ \\
\hline 75 & Guapuruvu & $\begin{array}{l}\text { Schizolobium parahyba (Vell.) S. F. } \\
\text { Blake }\end{array}$ & Fabaceae & A & $\mathrm{N}$ & 1 & 4 \\
\hline 76 & Helicônia & Heliconia rostrata Ruiz \& Pav. & Heliconiaceae & $\mathrm{B}$ & $\mathrm{N}$ & 6 & 15 \\
\hline 77 & Hera & Hedera helix $\mathrm{L}$. & Araliaceae & $\mathrm{H}$ & E & - & $2,4,21$ \\
\hline 78 & Hera-roxa & $\begin{array}{l}\text { Hemigraphis alternata (Burm. f.) T. } \\
\text { Anderson }\end{array}$ & Acanthaceae & $\mathrm{H}$ & $\mathrm{E}$ & - & 4 \\
\hline 79 & Hibísco & Hibiscus rosa-sinensis $\mathrm{L}$. & Malvaceae & $\mathrm{B}$ & $\mathrm{E}$ & 5 & 18 \\
\hline 80 & Hortênsia & Hydrangea macrophylla (Thunb.) Ser. & Hydrangeaceae & B & $\mathrm{E}$ & 15 & 18 \\
\hline 81 & Ipê-amarelo-miúdo & $\begin{array}{l}\text { Handroanthus chrysotrichus (Mart. ex } \\
\text { A. DC.) Mattos }\end{array}$ & Bignoniaceae & A & $\mathrm{N}$ & 73 & $\begin{array}{c}1,2,4,7,10,13,12 \\
15,16,19,20,23 \\
24,25\end{array}$ \\
\hline 82 & Ipê-amarelo-graúdo & Handroanthus albus (Cham.) Mattos & Bignoniaceae & A & $\mathrm{NC}$ & 64 & $\begin{array}{c}1,4,10,11,12,13 \\
14,15\end{array}$ \\
\hline 83 & Ipê-roxo & $\begin{array}{c}\text { Handroanthus heptaphyllus (Vell.) } \\
\text { Mattos }\end{array}$ & Bignoniaceae & A & $\mathrm{N}$ & 11 & 4,10 \\
\hline 84 & Ipê-verde & Cybistax antisyphillitica (Mart.) Mart. & Bignoniaceae & A & $\mathrm{N}$ & 1 & 14 \\
\hline 85 & Íris-amarelo & Iris pseudacorus L. & Iridaceae & $\mathrm{H}$ & $\mathrm{E}$ & - & 27 \\
\hline 86 & Iuca-gigante & Yucca gigantea Lem. & Asparagaceae & $\mathrm{B}$ & $\mathrm{E}$ & 1 & 11 \\
\hline 87 & Jabuticaba & Plinia trunciflora $\mathrm{O}$. Berg & Myrtaceae & A & $\mathrm{NC}$ & 3 & 4 \\
\hline 88 & Jacarandá-mimoso & Jacaranda mimosifolia D. Don & Bignoniaceae & A & $\mathrm{E}$ & 48 & $4,5,7,9,10,11,14,27$ \\
\hline 89 & Jasmim-amarelo & Jasminum mesnyi Hance & Oleaceae & $\mathrm{B}$ & $\mathrm{E}$ & 4 & 21 \\
\hline 90 & Jasmim-dos-poetas & Jasminum polyanthum Franch. & Oleaceae & $\mathrm{T}$ & E & & 21 \\
\hline 91 & Jerivá & $\begin{array}{c}\text { Syagrus romanzoffiana (Cham.) } \\
\text { Glassman }\end{array}$ & Arecaceae & A & $\mathrm{NC}$ & 113 & $\begin{array}{c}2,4,11,13,18,19 \\
21,31\end{array}$ \\
\hline 92 & Koleutéria & Koelreuteria paniculada Laxm. & Sapindaceae & A & $\mathrm{E}$ & 57 & $\begin{array}{c}2,11,12,15,16,21 \\
23,27\end{array}$ \\
\hline 93 & Leiteiro & Sapium glandulosum (L.) Morong & Euphorbiaceae & A & $\mathrm{N}$ & 2 & $19,25,27,29$ \\
\hline 94 & Limão-rosa & Citrus limon (L.) Burm. & Rutaceae & A & $\mathrm{E}$ & 2 & 27 \\
\hline 95 & Liquidambar & Liquidambar styraciflua $\mathrm{L}$. & Altingiaceae & A & $\mathrm{E}$ & 4 & 27 \\
\hline 96 & Maçaranduba & Persea pyrifolia Nees & Lauraceae & A & $\mathrm{N}$ & 2 & 11 \\
\hline 97 & Magnólia-branca & Magnolia grandiflora $\mathrm{L}$. & Magnoliaceae & A & $\mathrm{E}$ & 1 & 21 \\
\hline 98 & Manacá & Brunfelsia uniflora (Pohl) D. Don & Solanaceae & $\mathrm{B}$ & $\mathrm{NC}$ & 1 & 2 \\
\hline
\end{tabular}

Continua... 
TABELA 1: Continuação...

TABLE 1: Continued..

\begin{tabular}{|c|c|c|c|c|c|c|c|}
\hline N. & Nome popular & Nome científico & Família & F.V. & P. & $\begin{array}{l}\mathrm{N} . \\
\text { Ind. }\end{array}$ & Praças \\
\hline 99 & Monjoleiro & Anadenanthera colubrina (Vell.) Brenan & Fabaceae & A & $\mathrm{N}$ & 13 & $9,15,21,23,27$ \\
\hline 100 & Mulungú & Erythrina speciosa Andrews & Fabaceae & B & $\mathrm{NC}$ & 1 & 4 \\
\hline 101 & Nêspera & Eriobotrya japonica (Thunb.) Lindl. & Rosaceae & A & $\mathrm{E}$ & 7 & $12,13,18$ \\
\hline 102 & Oliveira & Olea europaea $\mathrm{L}$. & Oleaceae & A & $\mathrm{E}$ & 1 & 4 \\
\hline 103 & Paineira & Ceiba speciosa (A. St.-Hill.) Ravenna & Malvaceae & A & $\mathrm{N}$ & 62 & $\begin{array}{c}1,2,4,6,7,8,9,11 \\
13,15,19,21,22 \\
24,27\end{array}$ \\
\hline 104 & Palmeira-areca & $\begin{array}{c}\text { Dypsis lutescens (H. Wendl.) Beentje \& } \\
\text { J. Dransf. }\end{array}$ & Arecaceae & A & $\mathrm{E}$ & 45 & $2,4,10,18$ \\
\hline 105 & Palmeira-fenix & Phoenix roebelenii O’Brien & Arecaceae & A & $\mathrm{E}$ & 11 & 2,25 \\
\hline 106 & Palmeira-laca & Cyrstostachys renda Blume & Arecaceae & A & $\mathrm{E}$ & 6 & 2 \\
\hline 107 & Palmeira-leque & Licuala grandis H.Wendl. & Arecaceae & A & $\mathrm{E}$ & 13 & $2,4,24$ \\
\hline 108 & Palmeira-real & $\begin{array}{l}\text { Archontophoenix cunninghamiana } \mathrm{H} . \\
\text { Wendl. \& Drude }\end{array}$ & Arecaceae & A & $\mathrm{E}$ & 35 & 2,25 \\
\hline 109 & Palmito & Euterpe edulis Mart. & Arecaceae & $\mathrm{A}$ & $\mathrm{N}$ & 46 & $1,2,4,11$ \\
\hline 110 & Pata-de-vaca & Bauhinia forficata Link. & Fabaceae & A & $\mathrm{NC}$ & 4 & $4,29,30$ \\
\hline 111 & Pau-brasil & Caesalpinia echinata Lam. & Fabaceae & A & $\mathrm{N}$ & 2 & 2,4 \\
\hline 112 & Pau-ferro & Libidibia ferrea (Mart.) L.P. Queiroz & Fabaceae & A & $\mathrm{N}$ & 1 & 1 \\
\hline 113 & Pau-incenso & Pittosporum undulatum Vent. & Pittosporaceae & A & $\mathrm{E}$ & 8 & 7,10 \\
\hline 114 & Paxiúba & Socratea exorrhiza (Mart.) H. Wendl. & Arecaceae & A & $\mathrm{N}$ & 4 & 2 \\
\hline 115 & Pingo-de-ouro & Duranta erecta $\mathrm{L}$. & Verbenaceae & B & $\mathrm{N}$ & 17 & $4,20,27$ \\
\hline 116 & Pinheiro & Pinus elliottii Engelm. & Pinaceae & A & $\mathrm{E}$ & 2 & 11 \\
\hline 117 & Pinheiro & Pinus patula Schltdl. \& Cham. & Pinaceae & A & $\mathrm{E}$ & 4 & 24 \\
\hline 118 & Pinheiro-bravo & Podocarpus lambertii Klotzsch ex Endl. & Podocarpaceae & A & $\mathrm{NC}$ & 14 & $2,11,14,21$ \\
\hline 119 & Pinheiro-de-cook & $\begin{array}{c}\text { Araucaria columnaris (J.R. Forst.) } \\
\text { Hook. }\end{array}$ & Araucariaceae & A & $\mathrm{E}$ & 4 & 1,2 \\
\hline 120 & Piracanta & Pyracantha coccinea M. Roem. & Rosaceae & B & $\mathrm{E}$ & 2 & 21,24 \\
\hline 121 & Pitanga & Eugenia uniflora $\mathrm{L}$. & Myrtaceae & A & $\mathrm{NC}$ & 45 & $1,2,4,7,10,11,20,31$ \\
\hline 122 & Piteira & Opuntia sp. & Cactaceae & $\mathrm{H}$ & $\mathrm{E}$ & - & 11 \\
\hline 123 & Piteira-do-caribe & Agave angustifolia Haw. & Asparagaceae & B & $\mathrm{E}$ & 4 & 11,27 \\
\hline 124 & Primavera & Bougainvillea glabra Choisy & Nyctaginaceae & B & $\mathrm{N}$ & 1 & 11 \\
\hline 125 & Primavera-árvore & Bougainvillea arborea Glaz. & Nyctaginaceae & A & $\mathrm{N}$ & 26 & $1,2,4,7$ \\
\hline 126 & Robínia & Robinea pseudoacacia L. & Fabaceae & A & $\mathrm{E}$ & 7 & $1,7,20,21$ \\
\hline 127 & Rosa & Rosa sp. & Rosaceae & B & $\mathrm{E}$ & 1 & 4 \\
\hline 128 & Rosa-miniatura & Rosa chinensis Jacq. & Rosaceae & $\mathrm{B}$ & $\mathrm{E}$ & 1 & 23 \\
\hline 129 & Sabugueiro & Sambucus nigra $\mathrm{L}$. & Adoxaceae & $\mathrm{B}$ & $\mathrm{E}$ & 1 & 25 \\
\hline 130 & Sálvia & Salvia splendens Sellow ex Wied-Neuw. & Lamiaceae & $\mathrm{H}$ & $\mathrm{N}$ & - & $1,2,3,4,7,24$ \\
\hline 131 & Serissa & Serissa foetida (L. f.) Lam. & Rubiaceae & B & $\mathrm{E}$ & 2 & 21 \\
\hline 132 & Sibipiruna & Caesalpinia pluviosa DC. & Fabaceae & A & $\mathrm{N}$ & 14 & 21,23 \\
\hline 133 & Tagetes & Tagetes erecta $\mathrm{L}$. & Asteraceae & $\mathrm{H}$ & $\mathrm{E}$ & - & $1,2,4,7,24$ \\
\hline 134 & Tarumã & Vitex megapotamica (Spreng.) Moldenke & Lamiaceae & A & $\mathrm{NC}$ & 5 & 6,13 \\
\hline 135 & Timbaúva & $\begin{array}{c}\text { Enterolobium contortislliquum (Vell.) } \\
\text { Morong }\end{array}$ & Fabaceae & A & $\mathrm{N}$ & 9 & $7,12,25,27$ \\
\hline 136 & Tipuana & Tipuana tipu (Benth.) Kuntze & Fabaceae & $\mathrm{A}$ & $\mathrm{N}$ & 33 & $3,7,11,13,20,27$ \\
\hline 137 & Tuia & Thuja occidentalis $\mathrm{L}$. & Cupressaceae & A & $\mathrm{E}$ & 2 & 23 \\
\hline 138 & Uva-do-japão & Hovenia dulcis Thunb. & Rhamnaceae & A & $\mathrm{E}$ & 4 & 27,29 \\
\hline
\end{tabular}

Continua... 
TABELA 1: Continuação...

TABLE 1: Continued...

\begin{tabular}{|c|c|c|c|c|c|c|c|}
\hline N. & Nome popular & Nome científico & Família & F.V. & P. & $\begin{array}{l}\mathrm{N} . \\
\text { Ind. }\end{array}$ & Praças \\
\hline 139 & Uvarana & Cordyline spectabilis Kunth \& Bouché & Asparagaceae & A & $\mathrm{N}$ & 17 & $2,4,7,9,12,29$ \\
\hline 140 & Vacum & $\begin{array}{l}\text { Allophylus edulis (A. St.-Hil., A. Juss. \& } \\
\text { Cambess.) Radlk. }\end{array}$ & Sapindaceae & A & $\mathrm{NC}$ & 2 & 28 \\
\hline \multirow[t]{2}{*}{141} & Xaxim & Dicksonia sellowiana Hook. & Dicksoniaceae & B & $\mathrm{NC}$ & 20 & 2 \\
\hline & TOTAL & 141 ESPÉCIES & 58 FAMÍLIAS & & & 2.278 & \\
\hline
\end{tabular}

Em que: $\mathrm{F} . \mathrm{V} .=$ forma de vida: $\mathrm{A}=$ arbórea, $\mathrm{B}=$ arbustiva, $\mathrm{H}=$ herbácea, $\mathrm{T}=$ trepadeira; $\mathrm{P} .=$ procedência: $\mathrm{N}=$ nativa do Brasil, $\mathrm{NC}=$ nativa de Curitiba, $\mathrm{E}=$ exótica no Brasil; $\mathrm{N}^{\circ} \mathrm{IND} .=$ número de indivíduos, $(*)=$ não há contagem do número de indivíduos para as formas de vida herbácea e trepadeira; PRAÇAS=1-Tiradentes, 2-Carlos Gomes, 3-José Borges de Macedo, 4-Santos Andrade, 5-Garibaldi, 6-do Redentor, 7-da Espanha, 8-Pe. João Bagozzi, 9-Alfredo Andersen, 10-Villa Lobos, 11-Abílio de Abreu, 12-Itália, 13-Isaac Milder, 14-Presidente Eisenhower, 15-Tobias Bueno de Arruda, 16-Francisco R. A. de Macedo, 17-Nova República, 18-Lucia Bozza Pilatti, 19-Piazza San Marco, 20-Pe. Agostinho Legros, 21-do Japão, 22-Vívian Calopreso Braga, 23-Nelson Satenarski Monteiro, 24-Rio Iguaçu, 25-Pe. Dario Zampiero, 26-Profa. Rosa Kolody, 27-da Colonização Menonita, 28-Irene Pereira e Silva, 29-Loris Scorsin, 30-Emirados Árabes Unidos, 31-Domingas Bianco Stoco, 32-Prof. Dr. Manoel Lourenço Branco.

O número de espécies encontrado foi considerado alto quando comparado a estudos de levantamento florístico e inventário em áreas urbanas. Em praças, Harder (2002) identificou 55 espécies em Vinhedo SP, Mariano, Oliveira e Pereira (2008) encontraram 35 espécies em Ituperava - SP, Silva et al. (2011) identificaram 27 espécies em Santa Fé do Sul - SP, Souza et al. (2011) encontraram 64 espécies em Aracaju - SE, Santos, Silva e Souza (2011) identificaram 18 espécies em Crato - CE, e Kramer e Krupek (2012) encontraram 98 espécies em Guarapuava - PR. Outros estudos, como os de Dantas e Souza (2004) e Goés (2009), também apresentaram um número menor de espécies, encontrando 132 espécies na arborização urbana de Campina Grande - PB, e 82 espécies nas praças e na arborização de ruas de Salvador - BA, respectivamente.

Além da alta quantidade de espécies, também foi encontrada uma grande diversidade de famílias botânicas nas praças de Curitiba. A maioria das 58 famílias identificadas, 55,2\% do total, porém, teve ocorrência de uma única espécie, e apenas sete famílias, $12,1 \%$, são representadas por cinco ou mais espécies, conforme Figura 1.

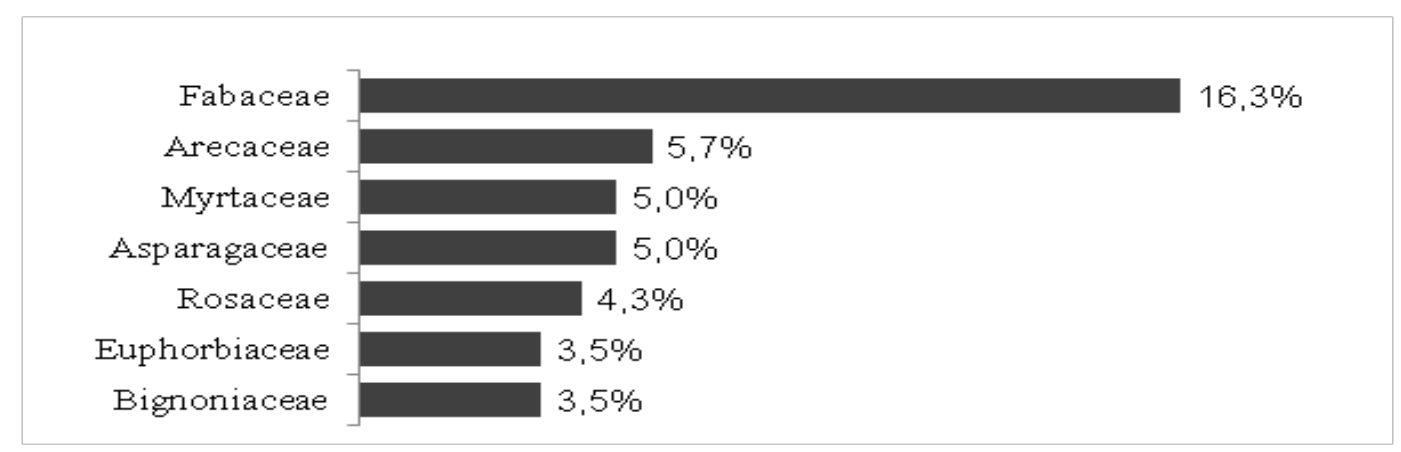

FIGURA 1: Famílias com maior representatividade de espécies nas praças de Curitiba - PR.

FIGURE 1: Families with greater species representation in the squares of Curitiba - PR state.

A família Fabaceae apresentou o maior número de espécies, 23, que representam 16,3\% do total de espécies presentes nas 32 praças amostradas. Goés (2009), Silva et al. (2011) e Kramer e Krupek (2012) encontraram esta família como a mais representativa de seus estudos, com 44,0\%, 25,9\% e 12,2\% do total de espécies, respectivamente. De acordo com Souza e Lorenzi (2005), Fabaceae é a principal família usada na arborização urbana em todo o Brasil. Na arborização de ruas de Curitiba, Bobrowski (2001) também identificou a família Fabaceae como a mais representativa, com 16,4\% do total de espécies, resultado bastante próximo ao encontrado por esta pesquisa. Os resultados encontrados tanto para a arborização de 
ruas quanto para as praças se justificam, pois, segundo Curitiba (2016b), o Horto Municipal da Barreirinha é o responsável pela produção de mudas para a arborização pública tanto de ruas quanto de áreas verdes de Curitiba, e Biondi e Leal (2008) encontraram 37 espécies de Fabaceae produzidas pelo horto, sendo a família de maior representatividade naquele local. As espécies encontradas nas praças foram classificadas de acordo com sua forma de vida: arbórea, arbustiva, herbácea ou trepadeira (Figura 2).

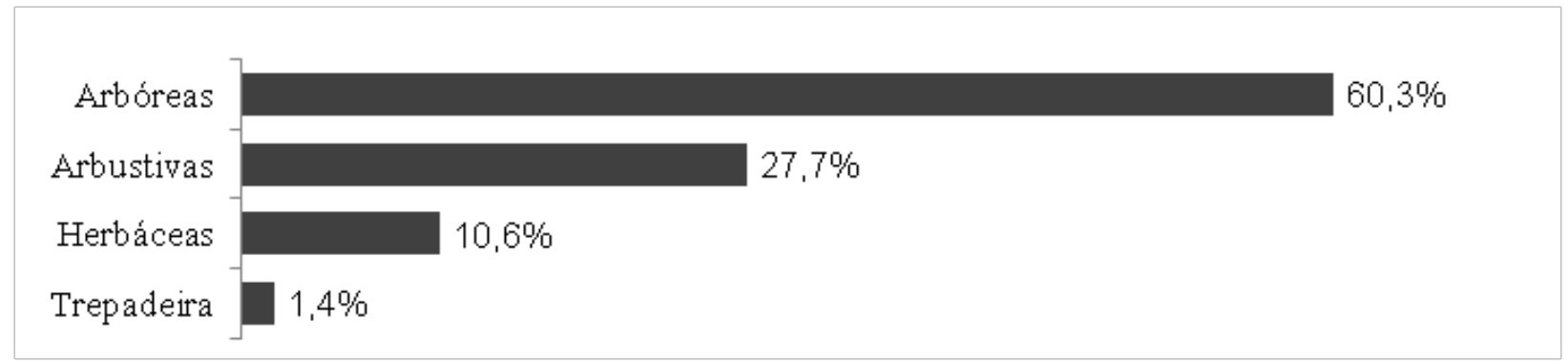

FIGURA 2: Formas de vida das espécies das praças amostradas em Curitiba - PR.

FIGURE 2: Species life forms of the sampled squares in Curitiba - PR state.

A maioria das espécies encontradas é arbórea, representando 60,3\%. Em segundo lugar estão as arbustivas, com 27,7\%, seguidas pelas as herbáceas e as trepadeiras, com 10,6\% e 1,4\%, respectivamente.

Em relação à procedência, as espécies foram divididas em exóticas, nativas do Brasil e nativas de Curitiba (Figura 3). A classificação da procedência de espécies em exóticas, nativas nacionais e nativas regionais é usada por diversos pesquisadores, como Biondi e Leal (2008), Goés (2009), e Isernhagem, Bourlegat e Carboni (2009), devido à preocupação em relação ao uso de espécies exóticas a ecossistemas.

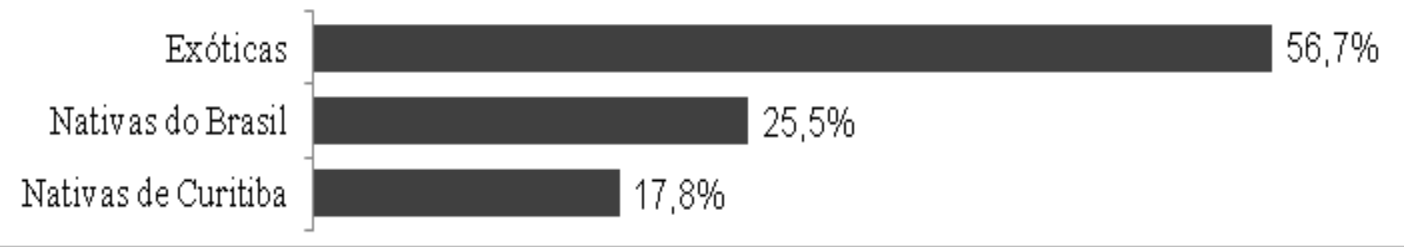

FIGURA 3: Procedência das espécies das praças amostradas em Curitiba - PR.

FIGURE 3: Species origins of the sampled squares in Curitiba - PR state.

A maioria das espécies encontradas nas praças amostradas é exótica, representando $56,7 \%$ do total de espécies, sendo as restantes nativas do Brasil ou de Curitiba, representando 25,5\% e 17,8\%, respectivamente.

Segundo Speth, Holdgate e Tolba (1992), espécies exóticas são aquelas que ocorrem em uma área fora de seu limite natural historicamente conhecido, como resultado da dispersão acidental ou intencional através de atividades humanas. Para Mack et al. (2000), o problema das espécies exóticas é que elas se estabelecem em novos territórios e persistem em detrimento de espécies próprias do ecossistema, causando alterações nos processos ecológicos.

De acordo com Ziller e Zalba (2007), espécies nativas, por sua vez, são espécies localizadas dentro dos limites de sua distribuição natural. Para estes autores, são os limites ambientais de cada ecossistema que caracterizam a procedência da espécie, e não os limites políticos, como é o caso das espécies nativas nacionais. Para estes autores, espécies movidas de um ecossistema para outro, mesmo dentro de um país, são tão exóticas quanto espécies estrangeiras, e também apresentam um potencial de risco e dano.

Sendo assim, pode-se considerar que $82,2 \%$ das espécies encontradas nas praças de Curitiba são exóticas ao ecossistema local, fazendo com que esta tipologia de área verde perca parte de seu potencial ecológico, especialmente na contribuição da conservação da biodiversidade da região, e em relação aos benefícios ocasionados pela vegetação nativa e biodiversidade. Dentre eles, Dias e Costa (2008) afirmam 
que as espécies nativas são responsáveis pela atração e conservação da fauna e contribuem para o equilíbrio ecológico, além de despertar na população um sentimento de valorização da flora e de identidade local.

Ainda assim, segundo Lorenzi et al. (2003), as espécies exóticas representam cerca de $80 \%$ das espécies usadas no Brasil. Em estudos de arborização urbana, Dantas e Souza (2004) encontraram 50,8\% de espécies exóticas, Mariano, Oliveira e Pereira (2008) 51,4\%, Goés (2009) 36,6\%, e Kramer e Krupek (2012), 48\%. Embora as praças de Curitiba apresentem uma maior diversidade de espécies quando comparadas a estes estudos, a proporção de espécies exóticas nas praças amostradas é superior: 56,7\%. $\mathrm{Na}$ arborização das ruas de Curitiba, Bobrowski (2011) também encontrou uma alta proporção de espécies exóticas, representando $54,1 \%$ do total.

Para Lorenzi (2002), a indisponibilidade de mudas é a principal dificuldade para o uso de espécies nativas. Já Silva et al. (2008) acreditam que o grande número de espécies exóticas usadas se deve, em parte, à falta de interesse dos órgãos públicos em incentivar e promover o plantio de espécies nativas da região. Porém, este não parece ser o caso de Curitiba, pois, segundo Biondi e Leal (2008), o Horto Municipal da Barreirinha produz principalmente espécies nativas - apenas $16,4 \%$ das espécies produzidas no horto são exóticas. Por isso, é difícil compreender o motivo do alto número de espécies exóticas encontrado na arborização da cidade.

Além de espécies exóticas, algumas espécies podem ser consideradas exóticas invasoras (MONTY; FLORENS; BAIDER, 2013). Segundo o Decreto Municipal 473/2008, espécies exóticas invasoras são introduzidas fora de sua área natural de distribuição, presente ou passada, cuja dispersão ameaça ecossistemas, habitat ou espécies e causam impactos ambientais, econômicos, sociais ou culturais. Em Curitiba, sete espécies são assim consideradas: alfeneiro (Ligustrum lucidum W.T. Aiton), amora (Morus nigra L.), cinamomo (Melia azedarach L.), eucalipto (Eucalyptus spp), pau-incenso (Pittosporum undulatum Vent.), pinheiro (Pinus spp) e uva-do-japão (Hovenia dulcis Thunb.). Todas estas espécies foram encontradas nas praças amostradas, representando 8,7\% das espécies exóticas, e 5,0\% do total de espécies.

De acordo com Ziller, Zenni e Graf Neto (2004), as espécies exóticas invasoras são introduzidas, adaptam-se e estabelecem-se em ecossistemas em que não ocorrem naturalmente, e passam a ocupar o espaço de espécies nativas, tendendo a tornarem-se dominantes e podendo causar impactos ambientais e socioeconômicos negativos. Blum, Borgo e Sampaio (2008) afirmam que as espécies exóticas invasoras são consideradas a segunda maior causa de extinção de espécies no planeta, afetando diretamente a biodiversidade, a economia e a saúde humana. Assim sendo, o Ministério do Meio Ambiente (BRASIL, 2006) recomenda o uso de estratégias e mecanismos para a eliminação, mitigação e controle de possíveis impactos causados por espécies exóticas invasoras. Para Biondi e Pedrosa-Macedo (2008), a administração pública deve gerar diretrizes para os departamentos que tratam de temas relacionados com a vegetação nas cidades, a fim de promover educação ambiental e práticas de manejo em áreas verdes e na arborização de ruas, fomentadas com informações técnico-científicas atuais, bom senso e respeito à vegetação nativa. A importância de uma vegetação de qualidade nas áreas verdes urbanas está fortemente relacionada com a conservação de ecossistemas locais e nacionais (BIONDI; MUELLER, 2013).

A procedência das espécies encontradas nas praças amostradas relacionada com a forma de vida de tais espécies está apresentada na Figura 4.

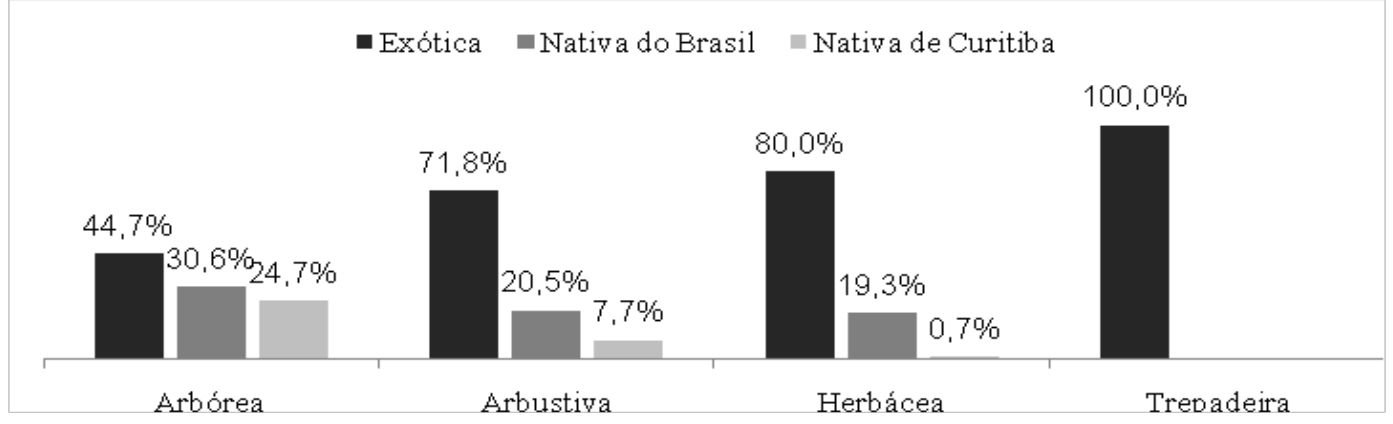

FIGURA 4: Procedência das espécies das praças amostradas em Curitiba - PR por forma de vida. FIGURE 4: Species origins of the sampled squares in Curitiba - PR state per life form. 
Das espécies arbóreas, 44,7\% são exóticas, 30,6\% são nativas do Brasil e 24,7\% são nativas de Curitiba. A proporção de espécies exóticas continua relativamente alta para as espécies arbóreas, entretanto, quando comparada com as demais formas de vida, percebe-se uma grande diferença. Das espécies arbustivas, $71,8 \%$ são exóticas. Das espécies herbáceas, este número chega a $80,0 \%$, e das trepadeiras, $100 \%$. Percebese, portanto, uma maior preocupação com a procedência das espécies arbóreas, em detrimento das demais formas de vida, talvez devido ao maior número de pesquisas, maior produção de mudas, e maior interesse econômico para as espécies arbóreas.

Em relação à frequência, a espécie que aparece em maior número de praças é a grama-sãocarlos (Axonopus compressus (Sw.) P. Beauv.), presente em 31 das 32 praças amostradas (96,9\%). A Praça do Redentor é a única praça em que esta espécie não aparece, devido à praça ter $99,1 \%$ de sua área impermeabilizada, e possuir apenas árvores em canteiros estreitos. A grama-são-carlos é nativa de Curitiba, sendo também conhecida como curitibana (GURGEL, 2003) e é uma das principais variedades de grama produzidas no Brasil (ZANON, 2003).

Entre as espécies arbóreas, aquelas com maior frequência nas praças estão apresentadas na Figura 5.

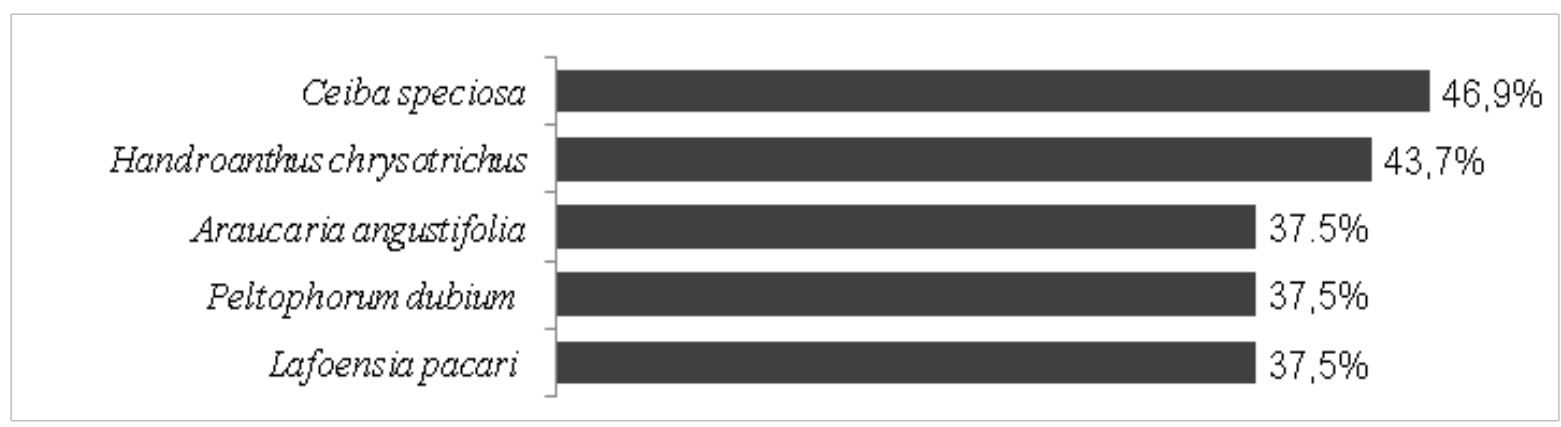

FIGURA 5: Frequência das espécies arbóreas nas praças amostradas em Curitiba - PR.

FIGURE 5: Frequency of tree species in the sampled squares of Curitiba - PR state.

Das espécies arbóreas, a paineira (Ceiba speciosa (A. St.-Hill.) Ravenna) é a que aparece no maior número de praças, 15 , o que representa $46,9 \%$ das praças amostradas, seguida do ipê-amarelo-miúdo (Handroanthus chrysotrichus (Mart. ex A. DC.) Mattos), em 43,7\% das praças, e a araucária (Araucaria angustifolia (Bertol.) Kuntze), a canafístula (Peltophorum dubium (Spreng.) Taub.) e o dedaleiro (Lafoensia pacari A. St.-Hill.), em 37,5\% das praças, cada uma.

Segundo Lorenzi (1992), a paineira é uma árvore de grande efeito ornamental, devido ao seu porte avantajado, beleza das flores e por apresentar florescimento abundante e prolongado. Costa e Kaminski (1990) afirmam que a paineira é frequentemente cultivada em parques, praças, jardins e avenidas das cidades brasileiras, como Brasília - DF e Foz do Iguaçu - PR. Curitiba então se une às demais cidades brasileiras em que a paineira aparece com frequência na arborização urbana. Todavia, não foram encontrados maiores motivos que justifiquem esta espécie como a mais frequente das praças da cidade.

O ipê-amarelo-miúdo, espécie que ficou em segundo lugar na frequência, é extremamente ornamental, principalmente quando perde as folhas e floresce, e em Curitiba é bastante utilizado na arborização de ruas e no paisagismo de parques e praças, além de ser considerada a flor nacional do Brasil (COBALCHINI, 1999). De acordo com Duarte e Ostos (2005), esta espécie carrega um simbolismo especial por carregar as mesmas cores da bandeira brasileira - verde e amarelo - e seus exemplares são como monumentos históricos, responsáveis pela identificação entre a nação e as árvores.

Enquanto o ipê-amarelo-miúdo é símbolo nacional, a araucária, espécie que ficou em terceiro lugar na frequência, é o símbolo máximo do Paraná e de Curitiba, aparecendo como uma imagem referência na construção da memória e da identidade social e cultural do estado e da cidade (CARVALHO, 2013). A araucária é uma espécie de grande efeito ornamental e paisagístico, com destaque para a beleza da copa nos vários estágios de seu desenvolvimento (CARVALHO, 2003).

Devido à importância do ipê-amarelo-miúdo e da araucária nas culturas brasileiras, paranaenses e 
curitibanas, e pelo fato da praça ser a tipologia de áreas verdes com maior relação com sua função social, esperava-se que estas espécies aparecessem em maior quantidade de praças do que a paineira. Além disso, o manacá (Brunfelsia uniflora (Pohl) D. Don), declarado como flor simbólica de Curitiba, segundo Lei Municipal 6.324/1982, está presente em apenas uma das praças amostradas.

Em relação à diversidade, as praças com maior número de espécies são apresentadas na Figura 6.

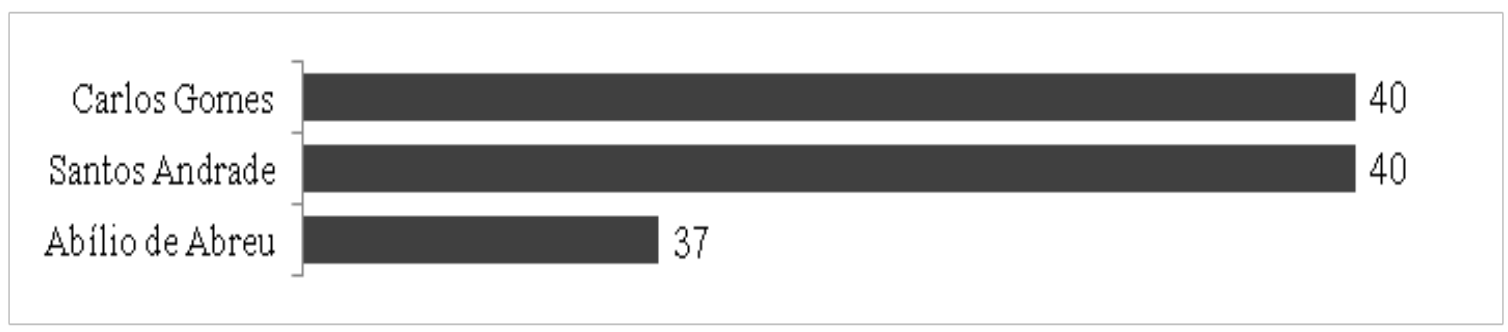

FIGURA 6: Praças de Curitiba - PR com maior número de espécies.

FIGURE 6: Squares of Curitiba - PR state which have the largest number of species.

As praças Carlos Gomes e Santos Andrade foram as praças amostradas com maior número de espécies, com 40 cada. A Praça Abílio de Abreu vem em seguida com 37 espécies. Estes números representam $28,4 \%$ e $26,2 \%$ do total de espécies encontradas.

A praça com a menor quantidade de espécies é a Praça Prof. Dr. Manoel Lourenço Branco, com $0,7 \%$ do total de espécies, porcentagem que representa apenas uma das 141 espécies. A única espécie ocorrente nesta praça é a grama-são-carlos, que aparece em 31 das 32 praças amostradas.

Para contagem do número de exemplares de cada espécie, levou-se em consideração apenas as espécies arbóreas e arbustivas. Foresti e Pereira (1987) afirmam que o conhecimento da quantidade da vegetação constitui uma base indispensável para a política de monitoramento e tomada de decisões para o melhoramento do ambiente das regiões intensamente urbanizadas.

Foram contabilizados 2.278 indivíduos em 124 espécies arbóreas e arbustivas. Este resultado representa uma média de aproximadamente 71 indivíduos por praça de Curitiba, ou um indivíduo a cada 98 $\mathrm{m}^{2}$ de praça. As dez espécies com o maior número de exemplares são apresentadas na Figura 7.

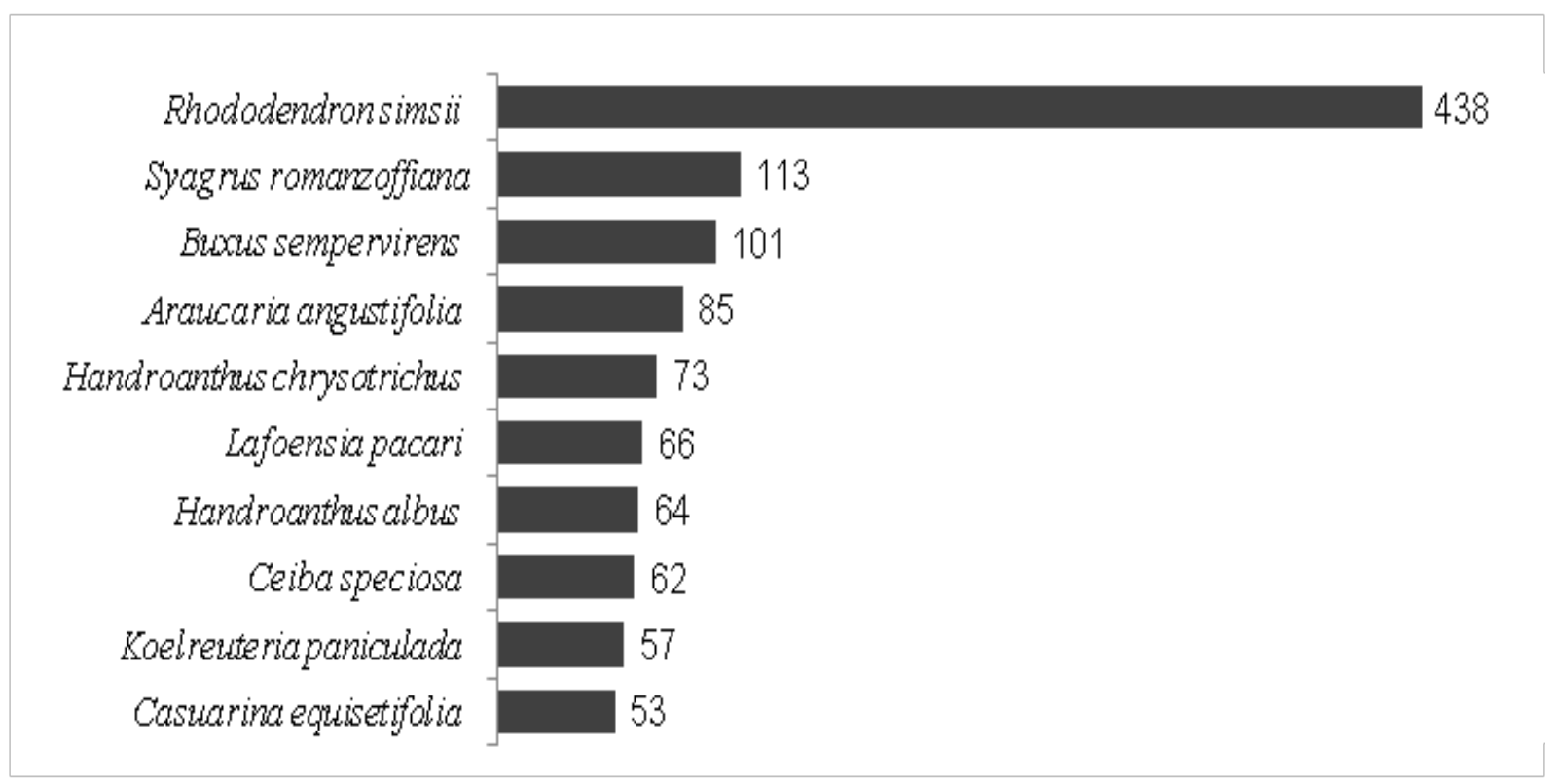

FIGURA 7: Espécies com maior número de exemplares nas praças de Curitiba - PR.

FIGURE 7: Species with greater number of individuals on the squares of Curitiba - PR. 
Das espécies de porte arbóreo e arbustivo, a azaleia (Rhododendron simsii Planch.) é a que mais apresentou exemplares, 438, representando 19,2\% de todos os indivíduos. Em segundo lugar, o jerivá (Syagrus romanzoffiana (Cham.) Glassman) apresentou 113 exemplares, representando 5,0\%, e em terceiro o buxinho (Buxus sempervirens L.), com 101 exemplares, ou 4,4\%. Das três espécies com maior número de exemplares, duas são espécies arbustivas. De acordo com Lira Filho (2002), as espécies arbustivas se destacam entre as plantas ornamentais. No paisagismo, os arbustos se sobressaem às árvores devido a sua plasticidade e suas formas, cores e volumes diferenciados.

$\mathrm{Na}$ composição das paisagens, as espécies arbustivas podem ser dispostas isoladamente ou agrupadas, em maciços ou cercas-vivas. Esta foi a utilização mais observada nas praças amostradas para a azaleia, espécie que apresentou o maior número de indivíduos. A azaleia é um arbusto resistente e ornamental, apresenta intensa floração nos meses de inverno, e por isso é muito usada em jardins e praças públicas (CLARKE, 1982; BELLÉ, 2013).

Além da azaleia e do buxinho, as demais espécies com maior número de exemplares são todas de vida arbórea. A araucária apresentou 85 indivíduos, ou 3,7\%, seguida do ipê-amarelo-miúdo, com 3,2\%, o dedaleiro, com 2,9\%, o ipê-amarelo-graúdo (Handroanthus albus (Cham.) Mattos), com 2,8\% e, por fim, a paineira, com $2,7 \%$.

Apesar de a paineira ocorrer em maior número de praças do que a araucária e o ipê-amarelo-miúdo, estas espécies possuem um maior número de exemplares. Este resultado era o esperado para esta pesquisa devido à importância simbólica e cultural da araucária e do ipê-amarelo-miúdo, discutidos anteriormente.

\section{CONCLUSÃO}

No geral, há um grande número de espécies e de famílias botânicas nas praças de Curitiba - PR, quando comparado a estudos de levantamento florístico e inventário em áreas urbanas. A maioria das espécies é de vida arbórea e exótica ao ecossistema original da região, mesmo existindo historicamente uma preocupação por parte do município com a arborização urbana da cidade. Todas as espécies consideradas exóticas invasoras por decreto municipal foram encontradas nas praças amostradas.

A espécie arbórea que ocorre no maior número de praças é a paineira (Ceiba speciosa (A. St.-Hill.) Ravenna), seguida por espécies de maior simbologia para a região: o ipê-amarelo-miúdo (Handroanthus chrysotrichus (Mart. ex A. DC.) Mattos) e a araucária (Araucaria angustifolia (Bertol.) Kuntze). A azaleia (Rhododendron simsii Planch.) é notadamente a espécie que apresenta o maior número de indivíduos.

Enquanto há praças com até 40 espécies diferentes, como a Carlos Gomes e a Santos Andrade, existem praças com baixíssima diversidade, como a Praça Prof. Dr. Manoel Lourenço Branco, que possui apenas uma espécie.

Sendo assim, recomenda-se a remoção de espécies exóticas invasoras e a valorização de espécies nativas de Curitiba - PR em suas praças, além do aumento da diversidade de espécies, permitindo assim que as praças desempenhem melhor seu potencial de promoção de benefícios ecológicos para a população urbana.

\section{REFERÊNCIAS}

ALVARES, C. A. et al. Köppen's climate classification map for Brazil. Meteorologische Zeitschrift, Stuttgart, v. 22, n. 6, p. 711-728, dez. 2013.

BAHLS, A. V. D. S. Praças de Curitiba: espaços verdes na paisagem urbana. Curitiba: Fundação Cultural de Curitiba, 2006. 193 p.

BELLÉ, S. Apostila de paisagismo. Bento Gonçalves: Instituto Federal de Educação, Ciência e Tecnologia do Rio Grande do Sul, 2013. 40 p.

BIONDI, D. Arborização urbana aplicada à educação ambiental nas escolas. Curitiba: Daniela Biondi, 2008. 120 p.

BIONDI, D.; ALTHAUS, M. Árvores de rua de Curitiba: cultivo e manejo. Curitiba: FUPEF, 2005. 179 p. BIONDI, D.; LEAL, L. Caracterização das plantas produzidas no Horto Municipal da Barreirinha - Curitiba/ PR. REVSBAU, Piracicaba, v. 3, n. 2, p. 20-36, jun. 2008. 
BIONDI, D.; MUELLER, E. Espécies arbóreas invasoras no paisagismo dos parques urbanos de Curitiba, PR. Floresta, Curitiba, v. 43, n. 1, p. 69-82, mar. 2013.

BIONDI, D.; PEDROSA-MACEDO, J. H. Plantas invasoras encontradas na área urbana de Curitiba (PR). Floresta, Curitiba, v. 38, n. 1, p. 129-144, mar. 2008.

BLUM, C. T.; BORGO, M.; SAMPAIO, A. C. F. Espécies exóticas invasoras na arborização urbana de Maringá, Paraná. REVSBAU, Piracicaba, v. 3, n. 2, p. 78-97, jun. 2008.

BOBROWSKI, R. Estrutura e dinâmica da arborização de ruas de Curitiba, Paraná, no período 1984 - 2010. 2011. 144 f. Dissertação (Mestrado em Engenharia Florestal) - Universidade Federal do Paraná, Curitiba, 2011.

BRASIL. Ministério do Meio Ambiente. Espécies exóticas invasoras: situação brasileira. Brasília: MMA, 2006. $24 \mathrm{p}$.

CARVALHO, P. E. R. Espécies arbóreas brasileiras. Colombo: Embrapa Florestas, 2003. 1040 p.

CARVALHO, A. I. D. Pinheiro-do-Paraná: símbolo de identificação cultural ou emblema de uma história de desflorestamento? In: SIMPÓSIO NACIONAL DE HISTÓRIA, 27., 2013, Natal. Anais... Natal: ANPUH, 2013. p. 1-11.

CLARKE, J. H. Getting started with rhododendrons and azaleas. Portland: Timber, 1982. 268 p.

COBALCHINI, J. L. Considerações sobre as doze espécies florestais mais utilizadas na arborização de ruas de Curitiba - PR. 1999. 150 f. Monografia (Especialista em Gerenciamento Ambiental na Indústria) - Universidade Federal do Paraná, Curitiba, 1999.

COSTA, C. S.; ERJAVEC, I. S.; MATHEY, J. Green spaces - a key resources for urban sustainability. The GreenKeys approach for developing green spaces. Urbani Izziv, Ljubljana, v. 19, n. 2, p. 199-211, dez. 2008.

COSTA, E. F.; KAMINSKI, N. L. Análise quali-quantitativa da arborização de ruas do conjunto habitacional "A" da Itaipu Binacional, Foz do Iguaçu - Paraná. In: ENCONTRO NACIONAL SOBRE ARBORIZAÇÃO URBANA, 3., 1990, Curitiba. Anais... Curitiba: FUPEF, 1990. p. 252-262.

CRISPIM, D. L. et al. Diagnóstico da arborização urbana do centro da cidade de Pombal-PB. Revista Verde, Mossoró, v. 9, n. 1, p. 191-196, mar. 2014.

CURITIBA (PR). Decreto n. 473, de 05 de junho de 2008. Define as espécies florestais consideradas como exóticas invasoras para o Município de Curitiba e dá outras providências. Diário Oficial do Município, Curitiba, 05 jun. 2008. Disponível em: <http://goo.gl/fxhWIO>. Acesso em: 01 fev. 2016.

CURITIBA (PR). Lei Municipal n. 6.324, de 12 de julho de 1982. Declara o manacá flor simbólica de Curitiba, revoga a Lei 6.262/1981 e dá outras providências. Diário Oficial do Município, Curitiba, 12 jul. 1982. Disponível em: <https://goo.gl/4KcBnN>. Acesso em: 01 fev. 2016.

CURITIBA (PR). Índice de área verde passa para $64,5 \mathrm{~m}^{2}$ por habitante. Curitiba: Prefeitura Municipal de Curitiba, [2016a]. Disponível em: <http://goo.gl/Kt9AHt>. Acesso em: 30 jan. 2016.

CURITIBA (PR). Horto Municipal da Barreirinha. [2016b]. Disponível em: <http://goo.gl/IzNrnc>. Acesso em: 30 jan. 2016c.

CURITIBA (PR). Prefeitura. Perfil da cidade de Curitiba. Curitiba: Prefeitura Municipal de Curitiba, [2016c]. Disponível em: <http://goo.gl/lMlwjZ>. Acesso em: 30 jan. 2016.

DANTAS, C. I.; SOUZA, C. M. C. Arborização urbana na cidade de Campina Grande - PB: inventário e suas espécies. Revista Bioterra, Campina Grande, v. 4, n. 2, p. 37-54, jul./dez. 2004.

DE ANGELIS, B. L.; DE ANGELIS NETO, G. Os elementos de desenho das praças de Maringá-PR. Acta Scientiarum, Maringá, v. 22, n. 5, p. 1445-1454, 2000.

DIAS, J.; COSTA, D. Sugestões de espécies arbóreas nativas ocorrentes no sul do estado do Paraná para fins ornamentais. União da Vitória: FAFIUV, 2008. 28 p.

DUARTE, R. H.; OSTOS, N. S. Entre ipês e eucaliptos. Revista Nómadas, Bogotá, n. 22, p. 74-85, abr. 2005.

FORESTI, C; PEREIRA, M. D. B. Utilização de índices vegetativos obtidos com dados do sistema TM LANDSAT no estudo ambiental urbano: cidade de São Paulo. São José dos Campos: INPE, 1987. 24 p. GOÉS, G. S. Arborização de ruas e praças em Salvador, BA: a luz da ecologia e permacultura. 2009. 127 f. Trabalho de Graduação (Bacharel em Ciências Biológicas) - Universidade Federal da Bahia, Salvador, 2009. 
GURGEL, R. G. A. Principais espécies e variedades de grama. In: SIMPÓSIO SOBRE GRAMADOS, 1., 2003, Botucatu. Anais... Botucatu: FCA; UNESP, 2003. CD-ROM.

HARDER, I. C. F. Inventário quali-quantitativo da arborização e infra-estrutura das praças da cidade de Vinhedo (SP). 2002. 140 f. Dissertação (Mestrado em Agronomia) - Universidade de São Paulo, Piracicaba, 2002.

IBGE. Características urbanísticas do entorno dos domicílios. Rio de Janeiro: IBGE, [2016a]. Disponível em: $<$ http://goo.gl/izXHgh>. Acesso em: 30 jan. 2016c.

IBGE. Censo 2010. Rio de Janeiro: IBGE, [2010]. Disponível em: $<$ http://goo.gl/IG7Htc $>$. Acesso em: 30 jan. 2016.

IBGE. Cidades: Curitiba. Rio de Janeiro: IBGE, [2016b]. Disponível em: <http://goo.gl/60xQjx>. Acesso em: 30 jan. 2016.

INSTITUTO DE PESQUISA E PLANEJAMENTO URBANO DE CURITIBA. Curitiba em dados. Curitiba: IPPUC, [2016]. Disponível em: <http://goo.gl/4IZHZg>. Acesso em: 30 jan. 2016.

ISERNHAGEM, I.; LE BOURLEGAT, J. M. G.; CARBONI, M. Trazendo a riqueza arbórea regional para dentro das cidades: possibilidades, limitações e benefícios. REVSBAU, Piracicaba, v. 4, n. 2, p. 117-138, jun. 2009.

KRAMER, J. A.; KRUPEK, R. A. Caracterização florística e ecológica da urbanização praças públicas do município de Guarapuava-PR. Revista Árvore, Viçosa, MG, v. 36, n. 4, p. 647-658, ago. 2012.

LIRA FILHO, J. A. Paisagismo: elementos de composição e estética. Viçosa, MG: Aprenda Fácil, 2002. 194 p. (Coleção jardinagem e paisagismo. Série planejamento paisagístico, v. 2).

LORENZI, H. Árvores brasileiras: manual de identificação e cultivo de plantas arbóreas do Brasil. 2. ed. Nova Odessa: Plantarum, 2002. 368 p.

LORENZI, H. et al. Árvores exóticas no Brasil: madeiras, ornamentais e aromáticas. 1. ed. Nova Odessa: Platarum, 2003. 368 p.

LORENZI, H.; SOUZA, H. M. Plantas ornamentais no Brasil: arbustivas, herbáceas e trepadeiras. 4. ed. Nova Odessa: Plantarum, 2008. 1088 p.

MACK R. N. et al. Biotic invasions: causes, epidemiology, global consequences, and control. Ecological Applications, Washington, v. 10, n. 3, p. 689-710, jun. 2000.

MARIANO, R. D. S.; OLIVEIRA, R. L. N.; PEREIRA, M. Inventário de arborização de 12 praças no município de Ituverava-SP. Nucleus, Ituverava, v. 5, n. 1, p. 210-224, abr. 2008.

MARTINI, A. Microclima e conforto térmico proporcionado pelas árvores de rua na cidade de Curitiba - PR. 2013. 129 f. Dissertação (Mestrado em Engenharia Florestal) - Universidade Federal do Paraná, Curitiba, 2013.

MILANO, M. S. Planejamento e replanejamento de arborização de ruas. In: ENCONTRO NACIONAL SOBRE ARBORIZAÇ̃̃O URBANA, 2., 1987, Maringá. Anais... Maringá: PMM, 1987. p. 1-8.

MONTY, M. L. F.; FLORENS, F. B. V.; BAIDER, C. Invasive alien plants elicit reduced production of flowers and fruits in various native forest species on the tropical island of Mauritius (Mascarenes, Indian Ocean). Tropical Conservation Science, Menlo Park, v. 6, n. 1, p. 35-49, mar. 2013.

OLIVEIRA, R. J. D. P. D.; BRUNE, A. Variação da densidade básica da madeira e capacidade de regeneração entre e dentro de origens de Eucalyptus grandis W. Hill ex-Maiden. Revista Árvore, Viçosa, MG, v. 9, n. 1, p. 40-48, 1985.

ROBBA, F.; MACEDO, S. S. Praças brasileiras. São Paulo: EDUSP, 2010. 312 p. (Coleção Quapá).

SANTOS, A. C. B. D.; SILVA, M. A. P. D.; SOUZA, R. K. D. Levantamento florístico das espécies utilizadas na arborização de praças no município de Crato, CE. Cadernos de Cultura e Ciência, Crato, v. 10, n. 1, p. 13-18, dez. 2011.

SECRETARIADO DA CONVENÇÃO DA DIVERSIDADE BIOLÓGICA. Cities and biodiversity outlook. Montreal: CDB, 2012. 64 p.

SILVA, A. F. et al. Levantamento florístico da área urbana de Santa Fé do Sul: praças e bairros Bela Vista e Santa Cruz. In: FÓRUM DE INICIAÇÃO CIENTÍFICA DA FUNEC, 1., 2011, Santa Fé do Sul. Anais... Santa Fé do Sul: FUNEC, 2011. CD-ROM.

SILVA, A. T. D. et al. As praças Dr. Augusto Silva e Leonardo Venerando Pereira, 1701 Lavras - MG, segundo a visão de seus frequentadores. Ciência e Agrotecnologia, Lavras, v. 32, n. 6, dez. 2008. 
SOUZA, A. L. D. et al. Diagnóstico quantitativo e qualitativo da arborização das praças de Aracaju, SE. Revista Árvore, Viçosa, MG, v. 35, n. 6, p. 1253-1263, dez. 2011.

SOUZA, V. C.; LORENZI, H. Botânica sistemática: guia ilustrado para identificação das famílias de angiospermas da flora brasileira, baseado em APG II. Nova Odessa: Plantarum, 2005. 640 p.

SPETH, J. C.; HOLDGATE, M. W.; TOLBA, M. K. A estratégia global da biodiversidade. Diretrizes de ação para estudar, salvar e usar de maneira sustentável e justa a riqueza biótica da terra. Rio de Janeiro: WRI; UICN; PNUMA, 1992. 232 p.

TROPICOS. Missouri Botanical Garden. [2015]. Disponível em: $<$ http://www.tropicos.org $>$. Acesso em: 10 dez. 2015.

VIEZZER, J. et al. Tipologia das áreas verdes de Curitiba. In: CONGRESSO FLORESTAL PARANAENSE, 4., 2012, Curitiba. Anais... Curitiba: Congresso Florestal Paranaense, 2012. CD-ROM.

VOLPE-FILIK, A.; SILVA, L. F.; LIMA, A. M. P. Avaliação da arborização de ruas do bairro São Dimas na cidade de Piracicaba-SP através de parâmetros qualitativos. REVSBAU, Piracicaba, v. 2, n. 1, p. 34-43, mar. 2007.

ZANON, M. E. O mercado de Gramas no Brasil, cadeia produtiva, situação atual e perspectivas. In: SIMPÓSIO SOBRE GRAMADOS, 1., 2003, Botucatu. Anais... Botucatu: FCA; Unesp, 2003. p. 1-12. ZILLER, S. R.; ZALBA, S. Propostas de ação para prevenção e controle de espécies exóticas invasoras. Natureza \& Conservação, Curitiba, v. 5, n. 2, p. 8-15, jul. 2007.

ZILLER, S. R.; ZENNI, R. D.; GRAF NETO, J. Invasões biológicas: introdução, impactos e espécies invasoras no Brasil. In: PEDROSA-MACEDO, J. H.; BREDOW, E. A. Princípios e rudimentos do controle biológico de plantas: coletânea. Curitiba: UFPR, 2004. p. 17-41. 